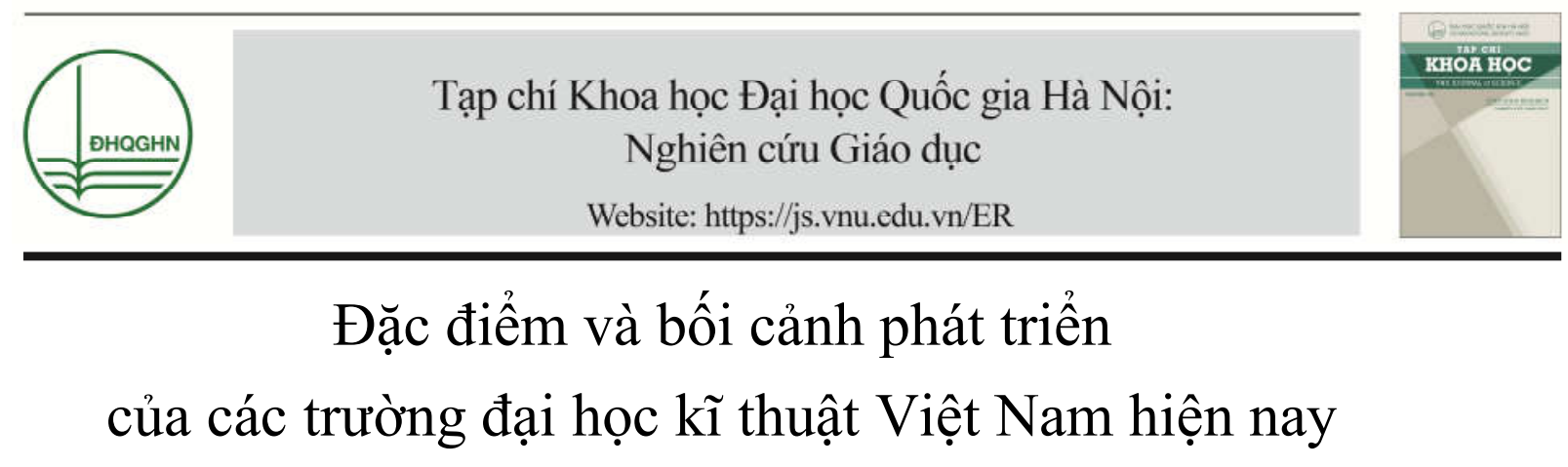

\author{
Vũ Tuấn Anh ${ }^{1, *}$, Nghiêm Xuân Huy ${ }^{2}$, Lê Thị Thương ${ }^{2}$ \\ ${ }^{1}$ Ban Khoa học Công nghệ, Đại học Quốc gia Hà Nội, 144 Xuân Thủy, Cầu Giấy, Hà Nội, Việt Nam \\ ${ }^{2}$ Viện Đảm bảo Chất luợng Giáo duc, Đại học Quốc gia Hà Nội, \\ 144 Xuân Thủy, Cầu Giấy, Hà Nội, Việt Nam \\ Nhận ngày 9 tháng 11 năm 2017 \\ Chỉnh sửa ngày 01 tháng 3 năm 2018; Chấp nhận đăng ngày 14 tháng 03 năm 2018
}

\begin{abstract}
Tóm tắt: Số liệu báo cáo của tổ chức OECD (The Organization for Economic Co-operation and Development) đã chỉ ra mối liên hệ rõ nét của khoa học công nghệ trong sự phát triển kinh tế - xã hội của một quốc gia. Trong mối liên hệ đó, giáo dục và đào tạo ngành khoa học kĩ thuật đóng vai trò chính yếu tạo ra nguồn nhân lực có tay nghề đáp ứng nhu cầu ngày càng lớn của khoa học công nghệ. Trên thế giới, những quốc gia kịp thời vận dụng đúng đắn mối liên hệ này, đầu tư mạnh mẽ vào giáo dục và đào tạo khoa học kĩ thuật đã tiến được những bước đáng kể trên con đường phát triển đất nước. Ở Việt Nam, giáo dục và đào tạo khoa học kĩ thuật đã bắt kịp xu hướng với số lượng trường đại học kĩ thuật không ngừng gia tăng. Tuy nhiên việc đầu tư phát triển các trường đại học kĩ thuật hiện nay chưa nhận được sự quan tâm tương xứng.
\end{abstract}

Tù khóa: Trường đại học kĩ thuật, cách mạng công nghiệp 4.0, giáo dục khởi nghiệp, chuyển giao công nghệ, bối cảnh phát triển khoa học công nghệ.

\section{Giới thiệu}

Thế giới đã trải qua ba cuộc đại cách mạng công nghiệp trong lịch sử, cuộc cách mạng lần thứ nhất bắt đầu với sự phát triển sản xuất hàng hóa của ngành công nghiệp dệt, và được đánh dấu với sự ra đời của động cơ hơi nước (1775), cuộc cách mạng lần thứ hai diễn ra cùng với sự tiến bộ vượt bậc của nền kinh tế và kĩ thuật được đánh dấu bằng động cơ đốt trong và máy móc sử dụng điện, cuộc cách mạng lần thứ ba

\footnotetext{
* Tác giả liên hệ. ĐT: 84-24-37547670 (726).

Email: vtanh@vnu.edu.vn

https://doi.org/10.25073/2588-1159/vnuer.4110
}

diễn ra cùng sự bùng nổ kinh tế và kĩ thuật toàn cầu được đánh dấu bằng máy vi tính và internet. Đến thế kỉ 21 nhân loại tiếp tục bắt đầu cuộc cách mạng công nghiệp thứ tư. Thành tựu của cuộc cách mạng công nghiệp này là những công nghệ mới như in $3 \mathrm{D}$, robot, trí tuệ nhân tạo, IoT, S.M.A.C, nano, sinh học, vật liệu mới,... Những diễn tiến không ngừng của các cuộc đại cách mạng công nghiệp đã khẳng định tầm quan trọng của khoa học kĩ thuật trong quá trình phát triển kinh tế - xã hội của nhân loại.

Số liệu báo cáo của tổ chức OECD được thống kê từ các quốc gia phát triển nhất toàn cầu đã chỉ ra mối liên hệ rõ nét của khoa học công nghệ trong sự phát triển kinh tế - xã hội 
của một đất nước [1]. Trong mối liên hệ đó, giáo dục đào tạo các ngành khoa học kĩ thuật đóng vai trò chính yếu tạo ra nguồn nhân lực có tay nghề đáp ứng nhu cầu ngày càng lớn của khoa học công nghệ. Trên thế giới, những quốc gia kịp thời vận dụng đúng đắn mối liên hệ này, đầu tư mạnh mẽ vào giáo dục và đào tạo khoa học kĩ thuật đã tiến được những bước đáng kể trên con đường phát triển đất nước. Các nước phát triển phương Tây đã sớm nhận ra tầm quan trọng của kĩ thuật và có những đầu tư rất lớn vào ngành khoa học này, đặc biệt trong lĩnh vực giáo dục đại học. Các nước phát triển mới của châu Á (Hàn Quốc, Singapore,...) cũng đã đầu tư mạnh vào giáo dục đào tạo ngành khoa học kĩ thuật trước khi được xếp vào nhóm các nước phát triển như hiện nay. Trong bối cảnh như vậy, các trường đại học kĩ thuật đóng vai trò đặc biệt quan trọng đối với việc xây dựng nguồn lực cũng như thúc đẩy tiến trình phát triển kinh tế - xã hôi.

Tại Việt Nam, trong sự tác động ngày càng mạnh mẽ của cuộc cách mạng công nghiệp lần thứ tư, các trường đại học kĩ thuật đang ở bối cảnh, trạng thái và đặc điểm phát triển như thế nào? Nhà nước và các bên liên quan cần làm gì để thúc đẩy sự phát triển cũng như nâng cao vai trò của các trường đại học kĩ thuật, qua đó góp phần đẩy nhanh tiến trình hội nhập với cuộc cách mạng công nghiệp lần thứ tư của Việt Nam? Để trả lời cho những câu hỏi này, chúng tôi thực hiện nghiên cứu: "Đặc điểm và bồi cảnh phát triển của các trường đại học kĩ thuật Việt Nam hiện nay".

\section{Phương pháp nghiên cứu}

Trong phạm vi bài báo này, khái niệm "trường đại học kĩ thuật" được xác định là những trường đại học có tuyển sinh ngành đào tạo thuộc các nhóm ngành Kĩ thuật, mã ngành đào tạo từ 5201 đến 5206 và 5290 theo quy định của Bộ Giáo dục và Đào tạo [2]. Theo đó, nhóm nghiên cứu lựa chọn danh sách 65 trường đại học có đào tạo các mã ngành này trên toàn quốc để tiến hành khảo sát. Nội dung khảo sát bao gồm: Cơ cấu tổ chức, định hướng phát triển, cơ cấu ngành nghề đào tạo, và cơ sở hạ tầng phục vụ nghiên cứu. Số liệu khảo sát thu thập từ số liệu được công khai trên website của các trường đại học, cơ sở dữ liệu thống kê của ngành và kết quả điều tra khảo sát của đề tài TTKHCN.ĐT.05-2016. Kết quả mẫu khảo sát thu được có cơ cấu như sau:

Co cấu mẫu theo loại hình sở hưu

Thống kê thực hiện trên 65 trường đại học kĩ thuật trên toàn quốc. Trong đó, số trường đại học kĩ thuật thuộc loại hình ngoài công lập là $15 / 65$ chiếm $23 \%$, còn lại 50 trường thuộc loại hình công lập, chiếm $77 \%$. Tổng số trường đại học ngoài công lập trên toàn quốc là 60 [3]. Như vậy số trường đại học kĩ thuật ngoài công lập chiếm $25 \%$ tổng số trường đại học ngoài công lập.

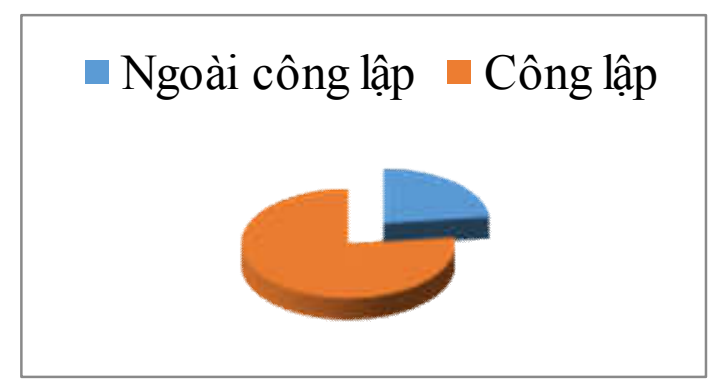

Biểu 1. Tỉ lệ Trường ĐH Kĩ thuật theo loại hình sở hữu.

Co cấu mẫu theo khu vự địa lí

Xét theo khu vực địa lí, các trường đại học kĩ thuật phân bố chủ yếu ở hai miền Bắc Nam và ít hơn đáng kể ở khu vực miền Trung. Miền Bắc có số lượng trường đại học kĩ thuật nhiều nhất là 28 trường chiếm $43 \%$, miền Nam có 25 trường chiếm $38 \%$, trong khi đó số trường ở miền Trung là 12 , chiếm $19 \%$.

Tại miền Bắc, các trường đại học kĩ thuật tập trung chủ yếu ở thủ đô Hà Nội và rải rác ở các vùng lân cận. Những trường ở Hà Nội cũng thường có quy môn lớn hơn, có số lượng sinh viên đông đảo (như Trường $\mathrm{DH}$ Công nghệ ĐHQGHN, Trường ĐH Khoa học Tự nhiên ĐHQGHN, Trường ĐH Bách Khoa Hà Nội, Học viện Công nghệ Bưu chính Viễn thông, Trường ĐH Giao thông Vận tải - cơ sở phía Bắc,...). 
Tại miền Trung, các trường đại học kĩ thuật chủ yếu là thành viên của hai đại học vùng gồm ĐH Huế và ĐH Đà Nẵng. Về mặt địa lí, số trường đại học kĩ thuật tập trung phần lớn ở khu vực Nam Trung Bộ, cụ thể là các tỉnh, thành phố như Khánh Hòa, Đà Nẵng, Phú Yên, Bình Định, Lâm Đồng, Kon Tum. Các trường khác nằm ở khu vực còn lại của miền Trung thuộc các tỉnh Thừa Thiên - Huế, Thanh Hóa, Hà Tĩnh, Quảng Bình, Nghệ An.

Tại miền Nam, xu hướng phân bố trường đại học kĩ thuật có nét tương đồng với khu vực miền Bắc.

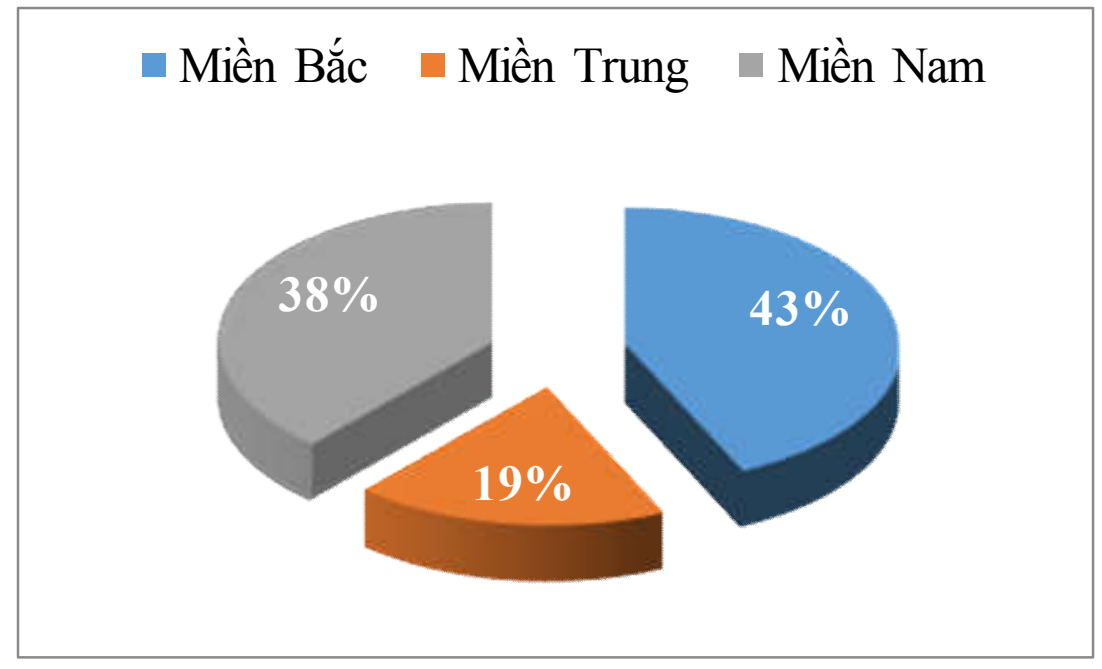

Biểu 2. Số lượng Trường Đại học Kĩ thuật phân chia theo khu vực địa lí.

Cụ thể các trường tập trung chủ yếu ở thành phố lớn là $\mathrm{TP}$. HCM (các trường: Trường $\mathrm{ĐH}$ Công nghệ TP HCM, Trường ĐH Giao thông Vận tải - Cơ sở phía Nam, Trường ĐH Sài Gòn,...) và rải rác ở các tỉnh, thành phố khác như Bình Dương, Cần Thơ, Long An...

\section{Kết quả nghiên cứu}

\section{1. Đặc điểm của các truoòng đại học kĩ thuật}

\subsubsection{Cơ cấu tổ chức}

Trong những năm gần đây, hệ thống giáo dục đại học Việt Nam đã phát triển rõ rệt về quy mô, đa dạng về loại hình trường và hình thức đào tạo; bước đầu điều chỉnh cơ cấu hệ thống, cải tiến chương trình, quy trình đào tạo; nguồn lực xã hội được huy động nhiều hơn và đạt được nhiều kêt quả tích cực; chất lượng đào tạo ở một số ngành, một số lĩ̀nh vực từng bước được cải thiện. Các trường đại học kĩ thuật Việt Nam cũng không nằm ngoài xu hướng này.
Các trường đại học kĩ thuật hiện nay, kể cả công lập hay ngoài công lập có cơ cấu tổ chức theo kiểu tuyến tính (line management). Kiểu cơ cấu này là một mô hình tổ chức quản lí, trong đó nhà quản trị ra quyết định và giám sát trực tiếp đối với cấp dưới và ngược lại, mỗi người cấp dưới chỉ nhận sự điều hành và chịu trách nhiệm trước một người lãnh đạo trực tiếp cấp trên. Theo mô hình này, cấp trên chịu trách nhiệm về kết quả công việc của cấp dưới, người đứng đầu trường đại học chịu trách nhiệm về hoạt động của nhà trường trước pháp luật và xã hội.

Mô hình chủ yếu của các trường đại học kĩ thuật hiện nay như sau:

Ban Giám hiệu đóng vai trò trung tâm trong các hoạt động điều hành của nhà trường. Dưới Ban Giám hiệu có các phòng, ban chức năng giúp việc cho Ban Giám hiệu, các đơn vị đào tạo và những tổ chức phục vụ cho đào tạo, nghiên cứu khoa học. 
Đối với các trường đại học ngoài công lập, bộ phận chỉ đạo trực tiếp Ban Giám hiệu nhà trường có khác biệt do có thêm Hội đồng Quản trị, là những cổ đông lớn nhất của trường. Trong các trường đại học kĩ thuật công lập, Ban Giám hiệu trường thường chịu sự chỉ đạo của Hội đồng trường và Đảng ủy thì ở các trường ngoài công lập, Ban Giám hiệu nhận sự chỉ đạo từ Hội đồng Quản trị. Ngoài ra, một bộ phận không thể thiếu là các Hội đồng và những tổ chức đoàn thể có vai trò tư vấn trong các hoạt động của Ban Giám hiệu.

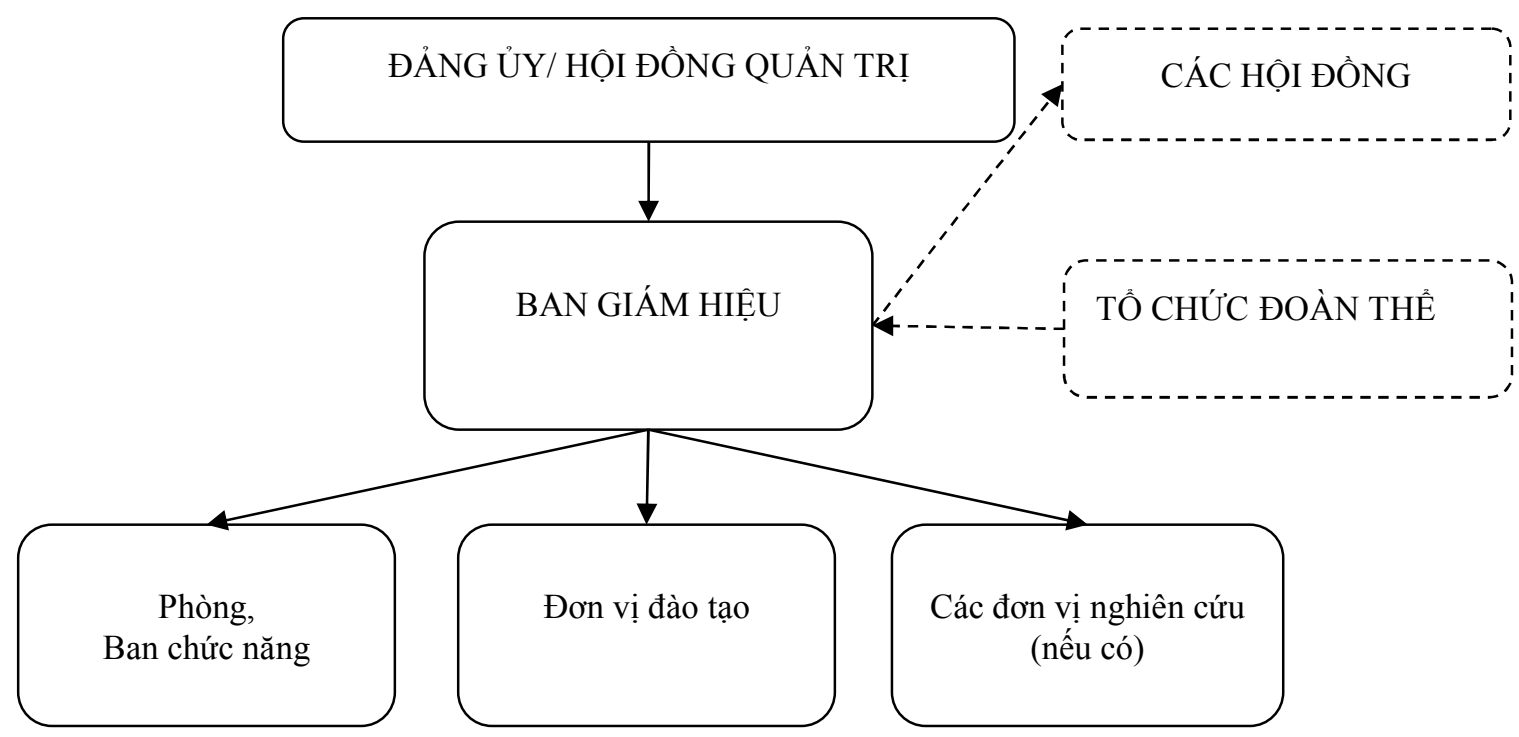

Hình 3. Cơ cấu tổ chức của các trường đại học kĩ thuật Việt Nam.

Các trường đại học công lập có đặc điểm chung là đều có đơn vị phục vụ đào tạo và nghiên cứu khoa học bao gồm viện nghiên cứu, trung tâm nghiên cứu, hoặc phòng thí nghiệm. Trong khi đó các trường đại học kỹ thuật ngoài công lập thiếu những đơn vị như vậy hoặc không công khai cụ thể trên trang thông tin điện tử của nhà trường.

Trên quá trình công nghiệp hóa, hiện đại hóa đất nước trong bối cảnh hội nhập quốc tế, Đảng và Nhà nước đã có những định hướng quan trọng trong công cuộc đổi mới căn bản, toàn diện giáo dục và đào tạo, trong khoa học và công nghệ $[4,5]$. Một trong những đổi mới quan trọng về quản lý giáo dục đại học trong giai đoạn hiện nay của Việt Nam là việc trao quyền tự chủ - tự chịu trách nhiệm trong các trường đại học phải gắn liền với " 3 công khai": công khai cam kết chất lượng giáo dục; công khai các điều kiện đảm bảo chất lượng giáo dục; công khai thu chi tài chính [6]. Phần lớn các trường đại học kỹ thuật đã thực hiện công khai trên trang điện tử của đơn vị, tuy nhiên một số trường đại học ngoài công lập quy mô nhỏ vẫn chưa thực hiện đúng quy định này. Bên cạnh đó, việc giám sát và đánh giá chất lượng hoạt động "ba công khai" cũng chưa được quan tâm đúng mức và triển khai hiệu quả.

Như vậy, hiệu quả của công tác quản lý nhà nước đối với các trường đại học kỹ thuật chưa thực sự cao. Trong thực tế, phương pháp quản lý nhà nước đối với các trường đại học, cao đẳng, một mặt, còn tập trung, chưa có quy chế phối hợp với các bộ, ngành, chưa phân cấp cho chính quyền địa phương, chưa tạo đủ điều kiện để các cơ sở đào tạo thực hiện quyền và trách nhiệm tự chủ. Mặt khác, công tác quản lý nhà nước chưa đánh giá được thực chất hoạt động cũng như việc thực hiện các chính sách giáo dục của Đảng và Nhà nước tại các trường đại 
học, chưa đánh giá được chất lượng giáo dục của toàn bộ hệ thống. Đồng thời, công tác quản lí ở các trường đại học kĩ thuật chưa phát huy được tính trách nhiệm và chủ động của đội ngũ nhà giáo, nhà quản lí và sinh viên.

\subsection{2. Định hướng phát triển}

Để tồn tại và phát triển, mỗi trường đại học đều phải xây dựng mục tiêu muốn vươn tới cũng như lộ trình để đi đến mục tiêu đó, và từ đó hình thành nên hệ thống chiến lược của nhà trường.

Khi xem xét định hướng phát triển của các trường đại học kĩ thuật thông qua sứ mạng, tầm nhìn, mục tiêu phát triển đã được tuyên bố, có thể nhận thấy một xu hướng chung là những trường đại học có quy mô lớn thường đặt cho mình sứ mạng, tầm nhìn, mục tiêu phát triển có tính vĩ mô với định hướng phát triển vươn ra tầm khu vực và quốc tế. Trong khi đó, những trường đại học kĩ thuật quy mô nhỏ có xu hướng gắn định hướng phát triển của trường với mục tiêu phục vụ cộng đồng và địa phương.

Một xu hướng chung khác là các trường đại học với quy mô lớn, tập trung ở khu vực đô thị quan trọng thường có tuyên bố về mục tiêu, sứ mạng, tầm nhìn được định hình rõ ràng, thể hiện được vị thế theo quy mô phát triển.

Các trường đại học kĩ thuật công lập thường tuyên bố mục tiêu, tôn chỉ gắn liền với định phát triển kinh tế xã hội của đất nước, hướng tới các mục tiêu giáo dục do Đảng và Nhà nước đã vạch ra, tham chiếu đến các văn kiện lớn của Đảng và Nhà nước. Theo đó, những nội dung sau thường được thể hiện và nhấn mạnh: “...điều chỉnh cơ cấu ngành nghề và trình độ đào tạo, nâng cao chất lượng đào tạo, đáp ứng nhu cầu nhân lực, nâng cao chất lượng đào tạo, đáp ứng nhu cầu nhân lực cho phát triển kinh tế - xã hội; đào tạo ra những con người có năng lực sáng tạo, tư duy độc lập, trách nhiệm công dân, đạo đức và kĩ năng nghề nghiệp, năng lực ngoại ngữ, kỉ luật lao động, tác phong công nghiệp, năng lực tự tạo việc làm và khả năng thích ứng với những biến động của thị trường lao động và một một phận có khả năng cạnh tranh trong khu vực và thế giới" [9]. Trong khi đó, các trường đại học kĩ thuật ngoài công lập, đặc biệt các trường có quy mô vừa và nhỏ, sự phản ánh các định hướng lớn trong công tác giáo dục, đào tạo của Đảng và Nhà nước chưa được thể hiện rõ nét trong sứ mệnh, tầm nhìn, mục tiêu và định hướng phát triển.

Như vậy, có thể thấy nhiều trường đại học kĩ thuật Việt Nam, đặc biệt là các trường có quy mô vừa, nhỏ và ngoài công lập thường thể hiện mục tiêu, định hướng chiến lược không rõ ràng và chưa gắn với định hướng phát triển chung của giáo dục đại học. Điều này dẫn đến hệ quả là các bên liên quan của nhà trường không thấu hiểu và thống nhất về mục tiêu, định hướng phát triển, ảnh hưởng tới chất lượng đào tạo và sự phát triển chung của nhà trường. Bên cạnh đó, do sự thiếu gắn kết với định hướng chung, các cơ sở giáo dục đại học này cũng dễ chịu sự tác động của mặt trái nền kinh tế thị trường, chú trọng đào tạo theo số đông mà không quan tâm đúng mức đến chất lượng đào tạo.

\subsubsection{Cơ cấu ngành nghề}

Trong nhiều năm qua, hầu như các trường đại học tuyển sinh và đào tạo theo nhu cầu của thị trường chứ chưa theo năng lực nội tại và định hướng phát triển nhân lực quốc gia và địa phương, dẫn đến sự mất cân đối các ngành nghề đào tạo, nội dung đào tạo nặng về lí thuyết khó áp dụng. Các ngành đào tạo gặp nhiều khó khăn trong khâu tuyển sinh, thiếu người học, chưa đảm bảo được sự cân đối về cơ cấu ngành nghề đào tạo.

Đối với những đại học cấp vùng và quốc gia, có đặc thù là tổ hợp nhiều trường thành viên do đó đào tạo đa ngành, đa nghề thì cơ cấu ngành nghề đào tạo rất đa dạng. Tuy nhiên, các trường đại học thành viên được thiết lập có quy mô, cơ cấu khá rõ ràng, xác định lĩnh vực đào tạo trọng tâm, chuyên sâu (ví dụ: kĩ thuật công nghệ, khoa học tự nhiên, khoa học xã hội, khoa học giáo dục, luật, kinh tế...). Đây còn gọi là xu hướng đa dạng hóa (diversification) của trường đại học đã được nhiều quốc gia có nền giáo dục tiên tiến trên thế giới áp dụng. $\mathrm{Xu}$ hướng này phát triển nhiều loại hình trường với cơ cấu đào tạo đa dạng về trình độ và ngành nghề theo hướng hàn lâm (academy) hoặc nghề nghiệp (professional). 
Theo khảo sát của nhóm nghiên cứu, có một hiện tượng là nhiều trường đại học tuyển sinh mã ngành kĩ thuật nhưng những ngành này lại không phải là hướng đào tạo chủ đạo của trường. Một số trường đại học xuất hiện các mã ngành đào tạo kĩ thuật để tuyển sinh cùng với những mã ngành đào tạo khác như: quản trị kinh doanh, tài chính ngân hàng, hóa sinh, hóa học, địa chất học, nông học,... Nhiều trường chỉ tuyển sinh một mã ngành đào tạo kĩ thuật duy nhất. Điều này ảnh hưởng tới hiệu quả đầu tư của trường vào các ngành đào tạo kĩ thuật phải gắn liền với những nguồn lực như phòng thí nghiệm, xưởng thí nghiệm,...

3.1.4. Cơ sở hạ tầng phục vụ nghiên cứu và đào tạo

Để tìm hiểu về cơ sở vật chất trường đại học kĩ thuật phục vụ nghiên cứu, đề tài đã xem xét 65 trường đại học kĩ thuật qua các mục cơ sở vật chất sau: Giảng đường/phòng học, thư viện, phòng thí nghiệm, phòng thực hành. Tuy nhiên, tại thời điểm khảo sát chúng tôi thu thập được dữ liệu của 56/65 trường đại học kĩ thuật đã thực hiện ba công khai trên trang điện tử chính thức của trường theo quy định của Bộ Giáo dục và Đào tạo [6]. Các trường còn lại chưa thực hiện công khai phần lớn là các trường đặc thù trực thuộc lực lượng vũ trang nhân dân, trường ngoài công lập hoặc một số trang điện tử không thể truy cập.

Xu hướng chung dễ nhận thấy nhất là các trường đại học ở khu vực ngoại thành thường có diện tích lớn hơn các trường đại học nội thành. Điều này khá dễ hiểu do khu trung tâm thành phố dân cư đông đúc nên diện tích quy hoạch cho các trường đại học không lớn. Các trường đại học trẻ, mới thành lập thường có sự đầu tư cơ sở vật chất về diện tích khuôn viên theo yêu cầu của xu thế đảm bảo chất lượng giáo dục hiện đại nên thường có diện tích lớn hơn so với các trường đại học lâu đời Việt Nam. 5 trường có diện tích lớn nhất bao gồm: Trường ĐH Dân lập Hải Phòng, Trường ĐH Mỏ - Địa chất, Trường ĐH Cần Thơ, Học viện Nông nghiệp Việt Nam, Trường ĐH Lâm nghiệp.

Bảng 1. Danh sách 5 trường đại học kĩ thuật có tổng diện tích lớn nhất

\begin{tabular}{lll}
\hline Trường đại học & Ngoài công lập & Diện tích (ha) \\
\hline Trường Đại học Dân lập Hải Phòng & $\mathrm{x}$ & $14.675,23$ \\
Trường Đại học Mỏ-Địa chất & 4159 \\
Trường Đại học Cần Thơ & 218,5369 \\
Học viện Nông nghiệp Việt Nam & 200,28 \\
Trường Đại học Lâm nghiệp & 165 \\
\hline
\end{tabular}

Mô hình lớp học thông minh hay giảng đường thông minh cũng đang từng bước phát triển tại Việt Nam với ưu điểm trực quan, sinh động và khả năng tương tác cao. Nhiều trường đại học đã áp dụng mô hình lớp học này, tuy nhiên số lượng này vẫn còn hạn chế do cần số vốn đầu tư lớn. Xét trên bình diện chung về giảng đường các trường đại học kĩ thuật trên cả nước, trước hết cần xem xét đển không gian nhà trường đầu tư cho giảng đường. Việc ưu tiên xây dựng các phòng học/giảng đường giúp sinh viên có đủ không gian học tập, hạn chế tình trạng sinh viên phải di chuyển từ cơ sở này đến cơ sở khác để học do trường thiếu phòng học/giảng đường dầंn đến phải đi thuê địa điểm bên ngoài. Các trường có diện tích xây dựng giảng đường lớn nhất gồm Trường ĐH Quốc tế Hồng Bàng, Trường ĐH Tôn Đức Thắng, Trường ĐH Công nghệ TP. HCM, Trường ĐH Cần Thơ, Trường ĐH Vinh. 
Bảng 2. Danh sách 5 trường đại học kĩ thuật có diện tích giảng đường lớn nhất

\begin{tabular}{lll}
\hline Trường đại học & Ngoài công lập & Diện tích $(\mathrm{m} 2)$ \\
\hline Trường Đại học Quốc tế Hồng Bàng & $\mathrm{x}$ & 77.601 \\
Trường Đại học Tôn Đức Thắng & & 61.850 \\
Trường Đại học Công nghệ TP. Hồ Chí Minh & $\mathrm{x}$ & 51.621 \\
Trường Đại học Cần Thơ & & $51.185,7$ \\
Trường Đại học Vinh & & 47.323 \\
\hline
\end{tabular}

Về vai trò của thư viện, có quan điểm cho rằng thư viện thường phù hợp với các trường khối khoa học xã hội hơn, đối với trường đại học kĩ thuật thì nên đầu tư vào phòng thí nghiệm, nhà xưởng thực hành. Tuy nhiên, thư viện đóng vai trò hết sức quan trọng trong việc cung cấp nguồn tài liệu đại cương và chuyên ngành, giúp sinh viên cũng như cán bộ nhà trường trong việc tự học, tự nghiên cứu. Có thể nói, thư viện là nơi phản ánh rõ nét nhất chất lượng và triển vọng của trường đại học bởi không có trường đại học nào chất lượng tốt mà thư viện lại nghèo nàn, thiếu thốn. Do đó, việc đầu tư không gian xây dựng thư viện, tạo môi trường tự học, tự nghiên cứu cho cán bộ và sinh viên trường đại học là hết sức cần thiết. Trong khảo sát của đề tài, các trường đầu tư không gian xây dựng thư viện lớn nhất có Trường ĐH Cần Thơ, Trường ĐH Tôn Đức Thắng, Trường ĐH Bách Khoa Hà Nội, Trường ĐH Đà Lạt, Trường ĐH Giao thông vận tải. Ngoài ra, quan sát trên chuỗi số liệu chung, chúng tôi cũng nhận thấy có xu hướng chung là các trường đại học kĩ thuật công lập thường có thư viện rộng lớn hơn các trường ngoài công lập.

Bảng 3. Danh sách 5 trường đại học kỹ thuật có diện tích thư viện lớn nhất

\begin{tabular}{|c|c|c|}
\hline Trường đại học & Ngoài công lập & Diện tích (m2) \\
\hline Trường Đại học Cần Thơ & & 12.276 \\
\hline Trường Đại học Tôn Đức Thắng & & 11.276 \\
\hline Trường Đại học Bách Khoa Hà Nội & & 8.502 \\
\hline Trường Đại học Đà Lạt & & 8.400 \\
\hline Trường Đại học Giao thông vận tải & & $7.816,9$ \\
\hline
\end{tabular}

Phòng thí nghiệm hay phòng thực nghiệm là một cơ sở được thiết kế, xây dựng nhằm cung cấp các điều kiện, có đảm bảo an toàn cho việc triển khai các thí nghiệm, thực nghiệm trên các lĩnh vực đặc biệt là các lĩnh vực tự nhiên (Sinh Lý - Hóa....) phục vụ cho mục đích nghiên cứu khoa học. Nếu không có đủ sự đầu tư cho phòng thí nghiệm, các bài giảng trên giảng đường chỉ mang tính lí thuyết, trừu tượng, dễ đào tạo ra thế hệ nguồn nhân lực giỏi lí thuyết mà thiếu thực hành. Đối với các trường đại học kĩ thuật, việc đầu tư cho phòng thí nghiệm lại càng quan trọng hơn. Theo kết quả khảo sát, 05 trường có diện tích phòng thí nghiệm lớn nhất là Trường ĐH Cần Thơ, Trường ĐH Bách khoa - ĐHQG TP. Hồ Chí Minh, Trường ĐH Bách khoa Hà Nội, Trường ĐH Khoa học Tự nhiên ĐHQG TP.Hồ Chí Minh, Trường ĐH Bách khoa - ĐH Đà Nẵng.

Các trường đại học kĩ thuật có diện tích xưởng tập/ thực hành lớn nhất gồm: Trường $\mathrm{H}$ Nha Trang, Trường ĐH Sư phạm Kĩ thuật TP. Hồ Chí Minh, Trường ĐH Thuỷ lợi, Trường ĐH Sao Đỏ, Trường ĐH Bách khoa Hà Nội.

Ngoài ra, quan sát trên chuỗi số liệu chung cho thấy các trường đại học kĩ thuật công lập thường có phòng thí nghiệm rộng lớn hơn các 
trường ngoài công lập, trong khi đối với xưởng tập/thực hành, xu hướng này không rõ nét.

Tuy nhiên, việc đưa vào khai thác diện tích đất đai tạo tiền đề cơ sở vật chất phục vụ cho các hoạt động học tập và nghiên cứu kĩ thuật lại không phụ thuộc vào tổng diện tích của trường. Nhiều trường đại học kĩ thuật, đặc biệt là các trường mới thành lập thường chưa khai thác được hết diện tích để đưa vào sử dụng. Một phần nguyên nhân là do quy mô hoạt động của trường chưa lớn, giảng viên và sinh viên chưa đông. Một phần khác là do thiếu kinh phí đầu tư xây dựng; vì trường mới thành lập nên chưa huy động được nhiều nguồn vốn, việc đầu tư vào cơ sở vật chất phục vụ cho nghiên cứu còn hạn chế.

Bảng 4. Danh sách 5 trường đại học kĩ thuật có diện tích phòng thí nghiệm lớn nhất

\begin{tabular}{|c|c|c|}
\hline Trường đại học & Ngoài công lập & Diện tích (m2) \\
\hline Trường Đại học Cần Thơ & & $38.436,48$ \\
\hline Trường Đại học Bách khoa - ĐHQG TP. HCM & & 21.976 \\
\hline Trường Đại học Bách khoa Hà Nội & & 15.842 \\
\hline Trường Đại học Khoa học Tự nhiên - ĐHQG TP.HCM & & 13.971 \\
\hline Trường Đại học Bách khoa - Đại học Đà Nẵng & & 12.917 \\
\hline
\end{tabular}

Bảng 5. Danh sách 5 trường đại học kỹ thuật có diện tích xưởng tập/ thực hành lớn nhất

\begin{tabular}{|c|c|c|}
\hline Trường đại học & Ngoài công lập & Diện tích (m2) \\
\hline Trường Đại học Nha Trang & & $271.756,7$ \\
\hline Trường Đại học Sư phạm Kĩ thuật TP. HCM & & 16.980 \\
\hline Trường Đại học Thuỷ lợi & & 14.470 \\
\hline Trường Đại học Sao Đỏ & & 11.938 \\
\hline Trường Đại học Bách khoa Hà Nội & & 7.671 \\
\hline
\end{tabular}

Không gian dành cho giảng đường/phòng học, thư viện, phòng thí nghiệm, xưởng thực hành trên tổng diện tích của trường thể hiện sự đầu tư của trường đại học vào cơ sở vật chất phục vụ nghiên cứu khoa học của trường. Theo đó, các trường đại học ưu tiên nhất cho giảng đường/ phòng học là Trường ĐH Quốc tế Hồng Bàng, Trường ĐH Công nghệ TP. HCM, Trường ĐH Tài nguyên và Môi trường Hà Nội, Trường ĐH Giao thông Vận tải TP. HCM, Trường ĐH Việt Đức.

Các trường ưu tiên cho thư viện: Trường ĐH Đà Lạt, Trường ĐH Nguyễn Tất Thành, Trường ĐH Khoa học - ĐH Huế, Trường ĐH Việt Đức, Trường ĐH Giao thông Vận tải.
Các trường ưu tiên cho phòng thí nghiệm: Trường ĐH Khoa học Tự nhiên - ĐHQGHN, Trường ĐH Đà Lạt, Trường ĐH Việt Đức, Trường ĐH Công nghệ TP. Hồ Chí Minh, Trường ĐH Khoa học - ĐH Huế.

Các trường ưu tiên cho xưởng thực hành: Trường ĐH Nha Trang, Trường $Đ H$ Giao thông Vận tải TP. Hồ Chí Minh, Trường ĐH Việt Đức, Trường ĐH Sư phạm Kĩ thuật TP. Hồ Chí Minh, Trường ĐH Công nghệ TP. Hồ Chí Minh.

Như vậy, nhìn chung các trường đại học kĩ thuật đã đầu tư không gian xây dựng cho các khu giảng đường/phòng học nhưng còn thiếu sự quan tâm đầu tư cần thiết cho thư viện, các phòng thí nghiệm, xưởng thực hành. 
Bảng 6. Danh sách 5 trường ưu tiên diện tích lớn nhất cho giảng đường/phòng học

\begin{tabular}{lll}
\hline Trường đại học & Ngoài công lập & Tỉ lệ (\%) \\
\hline Trường Đại học Quốc tế Hồng Bàng & $\mathrm{x}$ & 135,42 \\
Trường Đại học Công nghệ TP. HCM & $\mathrm{x}$ & 74,38 \\
Trường Đại học Tài nguyên và Môi trường Hà Nội & & 55,39 \\
Trường Đại học Giao thông Vận tải TP. HCM & 53,64 \\
Trường Đại học Việt Đức & 53,31 \\
\hline
\end{tabular}

Bảng 7. Danh sách 5 trường ưu tiên diện tích lớn nhất cho thư viện

\begin{tabular}{lll}
\hline Trường đại học & Ngoài công lập & Tỉ lệ (\%) \\
\hline Trường Đại học Đà Lạt & & 24,46 \\
Trường Đại học Nguyễn Tất Thành & x & 5,09 \\
Trường Đại học Khoa học - Đại Học Huế & & 4,68 \\
Trường Đại học Việt Đức & 4,11 \\
Trường Đại học Giao thông Vận tải & 3,61 \\
\hline
\end{tabular}

Bảng 8. Danh sách 5 trường ưu tiên diện tích lớn nhất cho phòng thí nghiệm

\begin{tabular}{lll}
\hline Trường đại học & Ngoài công lập & Tỉ lệ (\%) \\
\hline Trường Đại học Khoa học Tự nhiên - ĐHQGHN & 32,36 \\
Trường Đại học Đà Lạt & 31,71 \\
Trường Đại học Việt Đức & 14,20 \\
Trường Đại học Công nghệ TP. Hồ Chí Minh & x & 7,44 \\
Trường Đại học Khoa học - Đại Học Huế & 7,10 \\
\hline
\end{tabular}

Bảng 9. Danh sách 5 trường ưu tiên diện tích lớn nhất cho xưởng tập/ thực hành

\begin{tabular}{lll}
\hline Trường đại học & Ngoài công lập & Tỉ lệ (\%) \\
\hline Trường Đại học Nha Trang & & 52,67 \\
Trường Đại học Giao thông Vận tải TP. HCM & 17,23 \\
Trường Đại học Việt Đức & 10,28 \\
Trường Đại học Sư phạm Kĩ thuật TP. HCM & & 7,77 \\
Trường Đại học Công nghệ TP. HCM & x & 7,44 \\
\hline
\end{tabular}

\section{Kết luận và khuyến nghị}

Các trường đại học kĩ thuật có sự phân bố không đồng đều, tập trung 2 miền Nam Bắc hơn miền Trung, tập trung ở các thành phố lớn và thưa dần ở các vùng ngoại ô, các vùng cận; cơ cấu tổ chức phổ biến là cơ cấu khung; định hướng phát triển của trường tỉ lệ thuận với quy mô trường; đào tạo đa dạng ngành nghề dẫn đến chưa chuyên sâu đầu tư vào chuyên ngành kĩ thuật; và chưa có sự đầu tư không gian hợp lí vào thư viện, phòng thí nghiệm, xưởng tập/thực hành.

Nhằm tạo động lực thúc đẩy các trường đại học kĩ thuật phát triển hướng tới trở thành bộ phận góp phần quan trọng vào sự nghiệp công 
nghiệp hóa, hiện đại hóa đất nước, chúng tôi đưa ra một số khuyến nghị sau đây.

Thư nhất là, nâng cao chất lương hoạt động quản trị truờng đại hoc

Kết quả nghiên cứu cho thấy sự không đồng bộ trong mục tiêu và định hướng phát triển của các trường đại học kĩ thuật, đặc biệt là sự chưa thể hiện rõ sứ mệnh phục vụ phát triển nguồn nhân lực khoa học công nghệ kĩ thuật phục vụ tiến trình công nghiệp hóa, hiện đại hóa đất nước. Ở cấp độ hệ thống, việc rà soát, cập nhật và điều chỉnh tầm nhìn, sứ mệnh, chiến lược phát triển của nhà trường có ý nghĩa đặc biệt quan trọng, không những giúp nhà trường có định hướng phát triển đúng đẳn, mà còn tranh thủ được đầu tư của nhà nước và địa phương thông qua các chương trình, dự án mục tiêu quốc gia. Ở cấp độ chức năng, các trường đại học cần có những đầu tư, nghiên cứu xu thế trong đào tạo, nghiên cứu, thị trường lao động để từ đó thực hiện quy hoạch ngành nghề phù hợp, không ngừng nâng chất lượng đào tạo và nghiên cứu dựa trên phản hồi của các bên liên quan.

Thứ hai là, thúc đẩy giáo dục khởi nghiệp

Giáo dục khởi nghiệp là một xu hướng hiện nay của các trường đại học trên thế giới, đòi hỏi mức độ bao phủ rộng từ cấp vi mô (trong từng trường đại học nói chung và trường đại học kĩ thuật nói riêng) đến cấp vĩ mô (cấp quốc gia và liên quốc gia). Giáo dục khởi nghiệp không chỉ tạo điều kiện cho sinh viên khởi nghiệp ngay từ khi còn ngồi trên ghế nhà trường, mà còn khuyến khích tư duy đổi mới và năng lực đổi mới cho sinh viên [8]. Chính vì vậy, thông qua giáo dục khởi nghiệp các trường đại học có thể tạo ra cầu nối ngắn nhất đưa khoa học kĩ thuật nhanh chóng góp phần thúc đẩy phát triển đất nước.

Bên cạnh đó, giáo dục khởi nghiệp một khi được lồng ghép trong các chương trình giáo dục trong trường đại học kĩ thuật sẽ thu hút đông đảo các doanh nhân, các nhà quản lí tham gia giảng dạy các chương trình khởi nghiệp cũng như quảng bá được hình ảnh của trường đại học đến với nhà tuyển dụng. Bên cạnh đó, việc kết nối với các nhà tuyển dụng, các doanh nghiệp sẽ giúp các trường đại học kĩ thuật vô hình chung mở rộng phạm vi thực hành cho sinh viên cả về quy mô lẫn chất lượng.

Thư ba là, đổi mới chính sách và các định huớng quy hoạch đối với các truờng đại học kĩ thuật

Hiện nay, các trường đại học kĩ thuật tập trung 2 miền Nam, Bắc hơn miền Trung, tập trung ở các thành phố lớn và thưa dần ở các vùng ngoại $\hat{o}$, các vùng cận; Nhiều trường đào tạo đa dạng ngành nghề, lĩnh vực đào tạo không tập trung chuyên sâu vào kĩ thuật dẫn đến phân tán sự đầu tư của nhà trường theo nhiều lĩnh vực, chưa tập trung đầu tư cho cơ sở hạ tầng phục vụ đào tạo kĩ thuật. Vì vậy Đảng và Nhà nước cần có chính sách cụ thể trong quy hoạch sự phân bố các trường đại học kĩ thuật, tạo sự hài hòa, cân đối trong phân bố mạng lưới các trường đại học kĩ thuật giữa các vùng miền để gia tăng tiếp cận của người học đối với lĩnh vực ngành nghề này. Bên cạnh đó, cần quy hoạch rõ ràng ngành, lĩnh vực theo hướng tập trung, chuyên sâu ngành nghề đào tạo đối với các trường đại học, đặc biệt là các trường có quy mô vừa và nhỏ. Đồng thời, hỗ trợ trong lộ trình quy hoạch, phát triển, gắn với đối tượng khởi nghiệp sáng tạo và đổi mới sáng tạo và gắn được trong chuỗi giá trị phát triển sâu, rộng toàn cầu. Ngoài ra, chính sách về tự chủ trường đại học cũng cần được quan tâm đẩy mạnh để khuyến khích sáng tạo đồi mới, thúc đẩy nội lực của các trường đại học nói chung và trường đại học kĩ thuật nói riêng.

Thư tu là, đẩy mạh nội lục truờng đại học kĩ thuật

Các cơ chế quản lí, giám sát từ phía nhà nước đóng vai trò quan trọng nhưng đóng vai trò là yếu tố "bên ngoài", sự sáng tạo, chủ động của các trường đại học mới là yếu tố "bên trong" giúp đẩy mạnh sự phát triển của khoa học kĩ thuật, của nền công nghiệp hóa, hiện đại hóa đất nước [7]. Các trường đại học kĩ thuật cần đổi mới, sáng tạo liên tục từ năng lực quản lí đến phương thức giảng dạy, đào tạo ra các thế hệ nguồn nhân lực của tương lai, đáp ứng nhu cầu thị trường lao động ngày càng cao. Liên kết để nghiên cứu, sản xuất, thương mại hoá sản 
phẩm có lợi thế cạnh tranh cao, có tính tiêu thụ toàn cầu. Đầu tư hợp lí nguồn ngân sách và tranh thủ nguồn tài trợ từ bên ngoài để đầu tư cơ sở hạ tầng phục vụ đào tạo. Đổi mới chương trình đào tạo, tăng cường liên kết, hợp tác với doanh nghiệp, nhà tuyển dụng để tạo môi trường thuận lợi cho giáo dục khởi nghiệp trong trường đại học.

\section{Lời cảm ơn}

Chúng tôi xin trân trọng cảm ơn sự tài trợ của Bộ Khoa học và Công nghệ cho đề tài TTKHCN.ĐT.05-2016 để thực hiện nghiên cứu này.

\section{Tài liệu tham khảo}

[1] OECD, Science, Technology and Innovation in the New Economy, 9/2000.

[2] Thông tư số 14/2010/TT-BGDĐT ngày 27 tháng 4 năm 2010 của Bộ trưởng Bộ Giáo dục và Đào tạo ban hành Danh mục giáo dục, đào tạo cấp IV trình độ cao đẳng, đại học, có hiệu lực kể từ ngày 12 tháng 6 năm 2010, được sửa đồi, bổ sung bởi Thông tư số 32/2013/TT-BGDĐT ngày 05 tháng
8 năm 2013 của Bộ trưởng Bộ Giáo dục và Đào tạo, có hiệu lực kể từ ngày 20 tháng 9 năm 2013.

[3] Theo Số liệu Thống kê giáo dục đại học của Bộ Giáo dục và Đào tạo năm học 2015-2016 tại https://www.moet.gov.vn/thong-ke/Pages/thongko-giao-duc-dai-hoc.aspx?ItemID=4041 truy cập ngày 23/10/2017.

[4] Đảng Cộng sản Việt Nam, Nghị quyết về Đổi mới căn bản, toàn diện giáo dục và đào tạo, Nghị quyết số 29-NQ/TW ngày 04/11/2013.

[5] Đảng Cộng sản Việt Nam, Nghị quyết về Phát triển Khoa học và Công nghệ, Nghị quyết số 20NQ/TW ngày 31/10/2012.

[6] Thông tư số 09/2009/TT-BGDĐT ngày 07/5/2009 của Bộ trưởng Bộ Giáo dục và Đào tạo quy định về việc các đơn vị đào tạo trong hệ thống giáo dục quốc dân từ cấp mầm non đến giáo dục đại học thực hiện ba công khai trên trang điện tử của đơn vị.

[7] Fukazawa Yukichi, Khuyến học, Nhà Xuất bản Trẻ, TP. Hồ Chí Minh, 2004

[8] Phạm Tất Dong, Giáo dục và khởi nghiệp, bài viết chuyên đề, Hội khuyến học Việt Nam, 8/2016.

[9] Quyết định số 711/QĐ-TTg của Thủ tướng Chính phủ ngày 13/6/2012 về việc phê duyệt "Chiến lược phát triển giáo dục 2011-2020".

\title{
Characteristics and Development Context of Engineering Universities in Vietnam
}

\author{
Vu Tuan Anh ${ }^{1}$, Nghiem Xuan Huy ${ }^{2}$, Le Thi Thuong ${ }^{2}$ \\ ${ }^{1}$ VNU Science and Technology Department, 144 Xuan Thuy, Cau Giay, Hanoi, Vietnam \\ ${ }^{2}$ VNU Institute for Education Quality Assurance, 144 Xuan Thuy, Cau Giay, Hanoi, Vietnam
}

\begin{abstract}
The Organization for Economic Co-operation and Development's (OECD) reports show that science and technology plays a significant role in a nation's socio-economic development. Thus, education and training in the field of engineering and technology is crucial in forming and developing a labour force capable of adapting to the increasingly science and technology-driven context. Those countries with suitable engineering education and training policies have attained remarkable development. In Vietnam, the number of engineering universities has been increasing to keep pace with the trend. This paper aims at investigating the current status of engineering universities and proposing some recommendations for a successful development of this higher education section.
\end{abstract}

Keywords: Engineering universities, the Fourth Industrial Revolution, technology transfer, science and technology development context. 